\title{
Parametric Analysis of Seismic Behavior for Steel-to- Concrete Connection Subjected to Combined Moment and Shear Loading
}

\author{
Lei Xu, Qun Xie, and Chang-Liang Sun
}

\begin{abstract}
Post-installed anchorage is a widely used connection technology where the structural steel is connected with the concrete element by adhesive anchor especially in the field of strengthening and retrofitting engineering. ABAQUS software has been employed in this paper to analyze the seismic behavior of steel-to-concrete connections with consideration of different spacing and edge distance of anchor. The results show that there is strength reduction for steel-toconcrete connection under cyclic loading compared with static loading capacity. In parameter analysis of spacing, anchors with spacing 12d behave good performance in capacity and seismic energy dissipation. As for the study of edge distance, compared with static results the ultimate capacity of anchor in small edge distance has significant reduction because of incomplete concrete cone, connection with edge distance 10d under cyclic loading presents similar anchorage behavior with strength in static test. And the minimum value $8 \mathrm{~d}$ of edge distance is proposed for practical design.
\end{abstract}

Index Terms-Adhesive anchor, steel-to-concrete connection, seismic behavior, spacing, edge distance.

\section{INTRODUCTION}

Post-installed anchorage is a widely used technology where a structural steel is intended to connect with an existing concrete element especially in structure rehabilitation. As a reliable and economical fastener, adhesive anchor or bonded-in rebar plays an important role in seismic design of steel-to-concrete connection, while the anchorage behavior has significantly been affected by variable factors such as embedment depth, hole cleaning, concrete crack, etc. Currently many researchers have investigated the effect of parameters mentioned above on tensile behavior of single anchor. Dr. Zhou-dao Lu has experimentally and numerically studied the shear performance of four adhesive anchors, which mainly aims to investigate the impact of spacing and edge distance on the shear strength. Several methods to predict shear-loading capacity have been compared [1]. Dr. Lin-zhi Wu has experimentally studied the dynamic response for different anchor types and the results show that the anchors has different performance under dynamic loading[2]. Sang-Yun Kim studies the seismic and fatigue performance of anchor in cracked concrete[3]. A. Ghobarah et al. analyze the seismic behavior of different types expansion anchors and

Manuscript received December 15, 2015; revised March 21, 2016.

Lei $\mathrm{Xu}$ and Qun Xie is with School of Civil Engineering and Architecture, University of Jinan, China (e-mail: 1129114062@qq.com).

Chang-Liang Sun is with Jinan Billion Machinery and Equipment Co., Ltd, China. draw the conclusions that there is no significant reduction of tension and shear strength for expansion anchors even suffering strong earthquake [4]. Dieter Lotze investigates the seismic behavior of several types anchors including precast anchor, expansion anchor and undercut anchor under combined moment and shear loading, and the result compared with static behavior shows that failure mode is governed by the eccentric distance of shear load which would lead to poor strength in the case of small distance [5].Yong-Gang Zhang studies the seismic performance of undercut anchor and expansion anchor subjected to eccentric shear load and find out that dynamic strength has no drop compared with the static behavior exception larger ultimate lateral displacement [6].

However in most engineering applications anchors usually work in group and probably are subjected to combined action of bending moment and shear loads, which is quite different from the performance for single anchor in pure tension or shear loads [7]. For multiple-anchor more attention should be paid on the impact of spacing, edge distance as well as the ratio of shear span on the anchorage behavior and failure mode [8]. Little knowledge about the seismic response of anchor group under combined moment and shear loads is available until now [9]. For the purpose of understanding the behavior of anchor groups under reversed cycling loading, ABAQUS software is employed and a serial of 3D models are established to investigate the influence of variable parameters.

\section{Model Details}

In the numerical analysis a typical steel-to-concrete connection model composed by I-shaped steel beam, reinforced concrete block, four adhesive anchors and steel plate. To achieve the target of anchorage failure, the steel beam has been designed with sufficient strength to prevent yielding [10]. The dimensions of steel beam and reinforced concrete block are kept to be constants in all models. Adhesive anchor is employed as fasteners to connect steel beam and concrete base. The vertical distance between the top anchors and the bottom anchors is kept as a constant of $190 \mathrm{~mm}$. The I-shaped steel beam is $800 \mathrm{~mm}$ in length and the dimension of section is $400 \mathrm{~mm} \times 300 \mathrm{~mm} \times 8 \mathrm{~mm}$ $\times 12 \mathrm{~mm}$. The dimension of concrete base is height $800 \mathrm{~mm} \times$ width $360 \mathrm{~mm} \times$ depth $210 \mathrm{~mm}$. The diameter of anchor is $12 \mathrm{~mm}$ and the total length is $210 \mathrm{~mm}$ for embedment depth is $180 \mathrm{~mm}(15 \mathrm{~d})$. The steel plate's thickness for all models is $20 \mathrm{~mm}$ which could avoid unexpected failure [11]. The elastic modulus and yield strength of steal is $2.1 \times 10^{5} \mathrm{MPa}$ 
and $235 \mathrm{MPa}$ respectively, Linear harden model has been considered in stress-strain relationship of steel. For concrete property, damage-plastic model has been chosen and the strength grade is $\mathrm{C} 30$ with elastic modulus $2.7 \times 10^{4} \mathrm{MPa}$ and Poisson's ratio 0.167 . The target concrete compressive strength is $30 \mathrm{MPa}$ and this value is selected because it is representative of concrete strengths in practical engineering.

The element C3D8 is used for steel beam and anchor in model while C3D8R element for concrete. Binding constraint is considered to simulate the connection between steel plate and anchor and hard contact is used to analyze the interaction between steel plate and concrete base surface [12]. Two kinds of shear span ratio, 0.3 and 0.5 , are adopted to study the different modes of flexural failure and shearing failure. The cyclic loading in simulation is achieved by displacement application at the flange of steel beam to simulate the seismic action in each load-step and there are three cycles for each displacement value. 3D model is showed as Fig. 1.

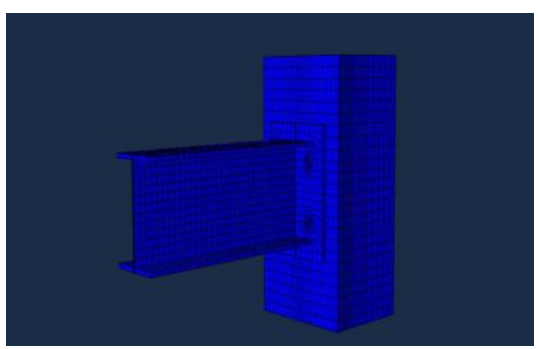

Fig. 1. Model detail.

\section{A. Analysis Results}

Two parameters has been considered in this analysis: edge distance and spacing. For anchor group spacing is an important variable to influence the anchorage strength which will lead to strength drop because of concrete overlap in the case of small spacing [13]. In order to understand the spacing effect, three kinds of spacing $5 \mathrm{~d}, 8 \mathrm{~d}, 12 \mathrm{~d}$, are adopted in three models respectively and to avoid the failure of concrete breakout enough edge distance is chosen as constant of $12 \mathrm{~d}$ in three cases. Edge distance is another key factor for anchor and the anchorage strength would decrease with concrete breakout failure instead of anchor steel failure if the edge distance is less than critical value [14], so three kinds of spacing $5 \mathrm{~d}, 7 \mathrm{~d}, 10 \mathrm{~d}$, are also considered in three models respectively and to avoid the failure of concrete cone overlap, enough spacing is chosen as constant of $16 \mathrm{~d}$ in three cases.

At initial stage of loading, the strain of anchor presents linear development and there is small displacement of steel beam. When the load reaches yield value, anchors in tensile zone reaches yield strength first and the strain increases abruptly. With the increase of load, displacement of anchor increases constantly and the anchor begin rotating round the tension zone, which generates gap between steel plate and surface of concrete block. When the load increases to ultimate value, the concrete around anchors in tension zone develops cone shape fully, and anchors reaches yield and damages lastly. The final failure modes are all reinforcement yielding which indicates a ductile failure. Displacement of small shell-shaped concrete cone in the surface of block that around the anchors is not significant.
Final deflection of steel beam is presented in Fig. 2 and the longitudinal displacement of bonded-in rebar is shown in Fig. 3.

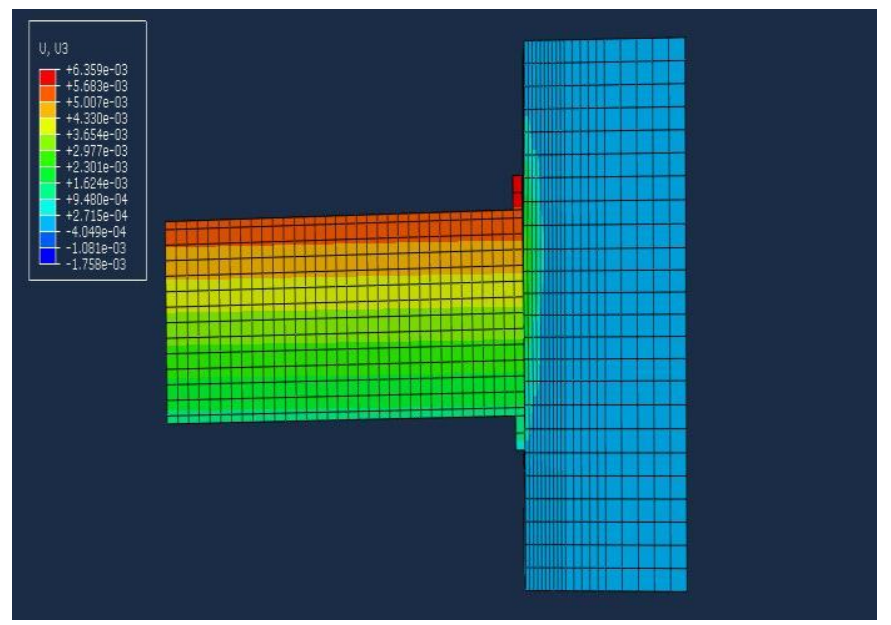

Fig. 2. Deflection of steel beam.

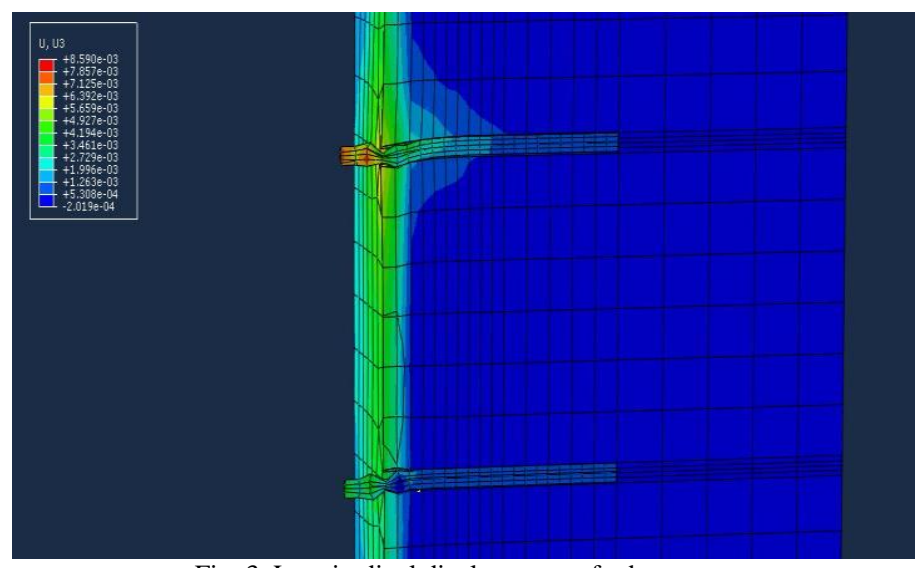

Fig. 3. Longitudinal displacement of rebar.

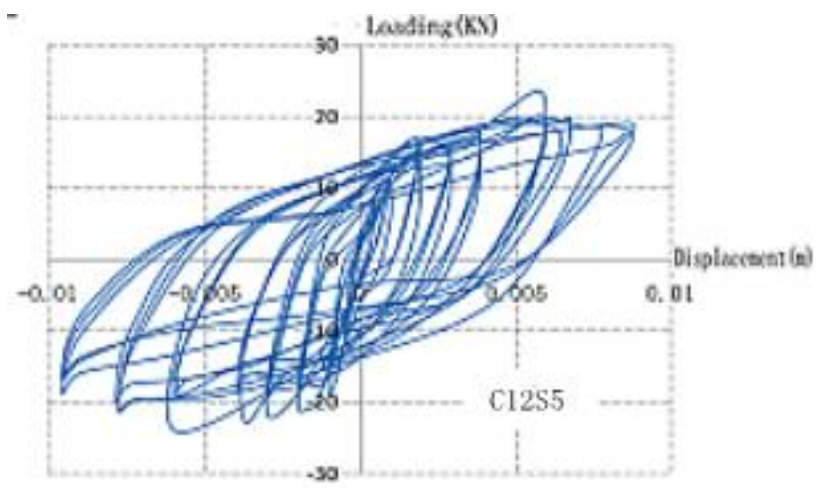

(a)

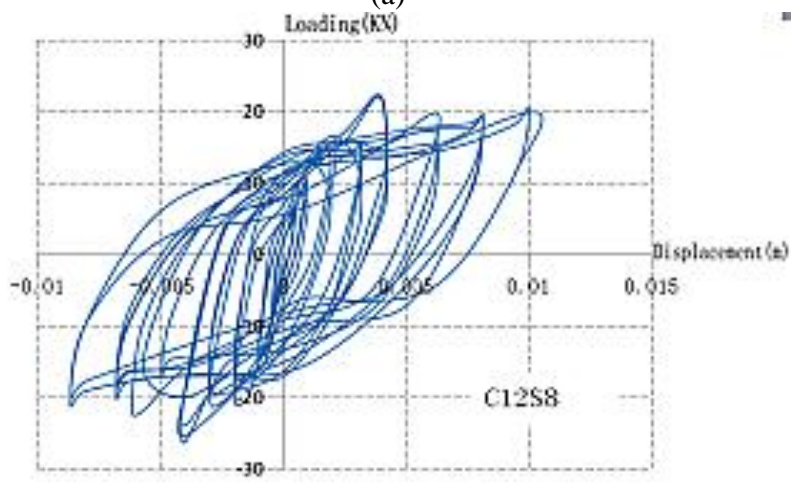

(b) 


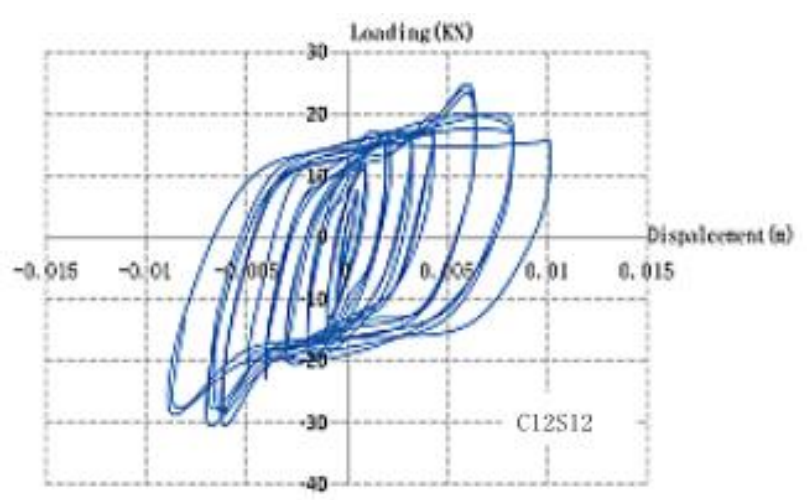

(c)

Fig. 4. Hysteresis curves under different spacing.

Experimental results for connections with different spacing are listed in Table I. Skeleton curves and hysteresis curves of models under different spacing are shown in the Figure 4 and Figure 5 respectively.Conclusion can be drawn that all hysteresis curves of different spacing behave satisfactory shapes and the displacements of the loaded end of anchor were small which indicates that the connections have good rigidity. And there is no significant loss of loading capacity even after peak value, which proves that the connections have good capacity of energy- dissipation. Anchorage strength of spacing $12 \mathrm{~d}$ is much bigger than strength of two other spacing, and the minimum value of spacing for multiple anchors should be 10d otherwise concrete cone failure would take place.

TABLE I: COMPARISON OF EXPERIMENTAL RESULTS FOR DIFFERENT

\begin{tabular}{|c|c|c|c|c|}
\hline \multirow{4}{*}{ parameters } & Number & $\begin{array}{c}\text { Yielding } \\
\text { strength } \\
(\mathrm{kN})\end{array}$ & $\begin{array}{c}\text { Ultimate } \\
\text { strength } \\
(\mathrm{kN})\end{array}$ & $\begin{array}{c}\text { Failure } \\
\text { mode }\end{array}$ \\
\hline \multirow{3}{*}{ Spacing } & $\mathrm{C} 12 \mathrm{~S} 5$ & 17.11 & 24.12 & $\begin{array}{c}\text { anchor } \\
\text { fracture }\end{array}$ \\
\cline { 2 - 5 } & $\mathrm{C} 12 \mathrm{~S} 8$ & 16.00 & 25.41 & $\begin{array}{c}\text { anchor } \\
\text { fracture }\end{array}$ \\
\cline { 2 - 5 } & $\mathrm{C} 12 \mathrm{~S} 12$ & 16.46 & 30.4 & $\begin{array}{c}\text { anchor } \\
\text { fracture }\end{array}$ \\
\hline
\end{tabular}

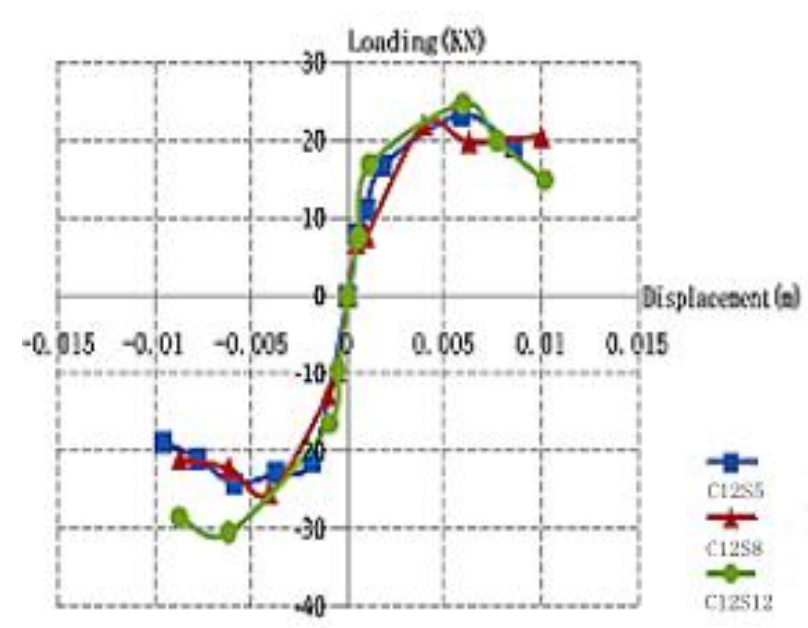

Fig. 5. Skeleton curves under different spacing.

Fig. 6 shows the load-displacement comparisons for three kinds of spacing in static and dynamic loading respectively. For the model with spacing $5 \mathrm{~d}$, the strength had a reduction at $15 \%$ compared with static test, and the rigidity decreases obviously at the initial load, which can be explained with the reason that spacing distance is not big enough to guarantee the generation of complete concrete cone which indicates that $5 \mathrm{~d}$ for spacing distance could not meet strength requirement. As for the two other spacing $8 \mathrm{~d}$ and $12 \mathrm{~d}$, both rigidity has loss at different levels, but no significant decline in capacity.

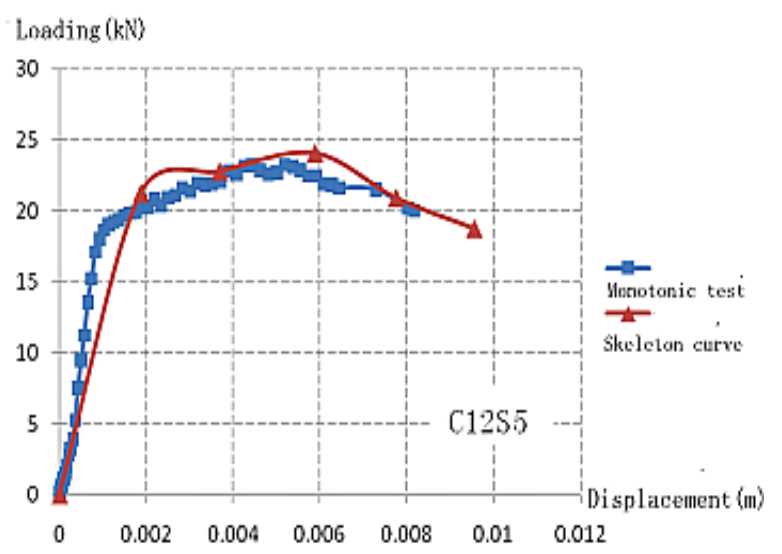

(a)

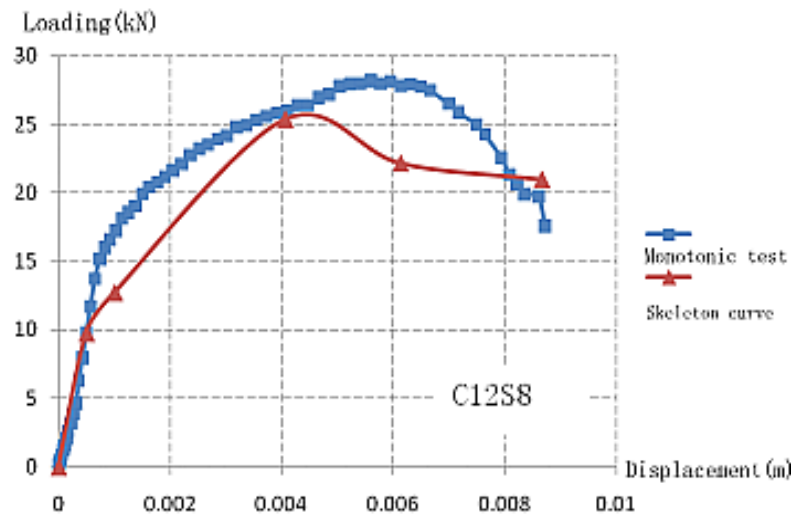

(b)

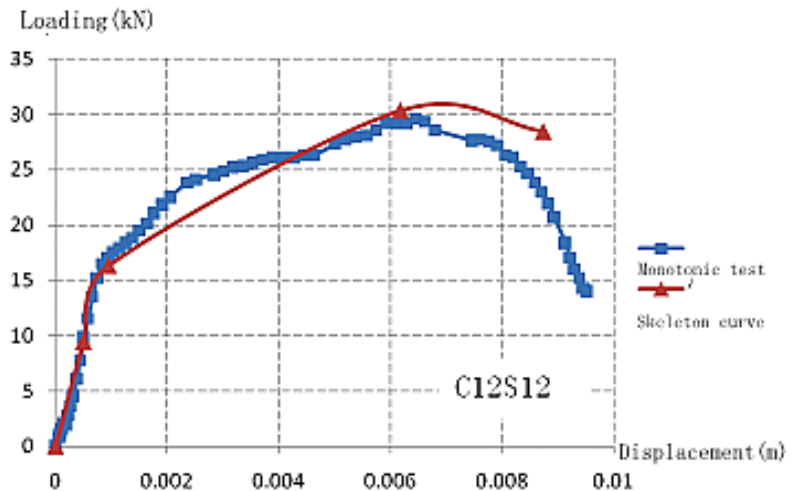

(c)

Fig. 6. Load-displacement comparisons for three kinds of spacing in static and dynamic loading.

Experimental results for connections with different edge distances are listed in Table II. In concrete stress contour for three edge distances, there is obvious concrete overlap for $5 \mathrm{~d}$ which indicates that the anchor strength probably couldn't develop and the potentially combined concrete cone failure would occur. There are two relatively independent concrete cone shapes in the case of $7 \mathrm{~d}$ and there is a small part of concrete overlap. For the case of $10 \mathrm{~d}$, each anchor can develop full steel strength and individual concrete cone. Fig. 7 is the comparison of hysteresis curves 
and skeleton curves for three edge distances and anchorage strength for edge distance $5 \mathrm{~d}$ is slightly lower than two others, the minimum value of edge distance for multiple anchors is suggested as $8 \mathrm{~d}$. As for the two other edge distances, $7 \mathrm{~d}$ and $10 \mathrm{~d}$, which have almost same strength, more edge distance won't provide better deformation ability.

\begin{tabular}{|c|c|c|c|c|}
\multicolumn{5}{c|}{ TABLE II: COMPARISON OF EXPERIMENTAL RESULTS } \\
\hline \multirow{2}{*}{ parameters } & Number & $\begin{array}{c}\text { Yielding } \\
\text { strength } \\
(\mathrm{kN})\end{array}$ & $\begin{array}{c}\text { Ultimate } \\
\text { strength } \\
(\mathrm{kN})\end{array}$ & $\begin{array}{c}\text { Failure } \\
\text { mode }\end{array}$ \\
\hline \multirow{2}{*}{$\begin{array}{c}\text { Edge } \\
\text { distance }\end{array}$} & $\mathrm{C} 5 \mathrm{~S} 16$ & 14.90 & 24.77 & $\begin{array}{c}\text { anchor } \\
\text { fracture }\end{array}$ \\
\cline { 2 - 5 } & $\mathrm{C} 7 \mathrm{~S} 16$ & 16.10 & 28.41 & $\begin{array}{c}\text { anchor } \\
\text { fracture }\end{array}$ \\
\cline { 2 - 5 } & $\mathrm{C} 10 \mathrm{~S} 16$ & 15.98 & 28.5 & $\begin{array}{c}\text { anchor } \\
\text { fracture }\end{array}$ \\
\hline
\end{tabular}

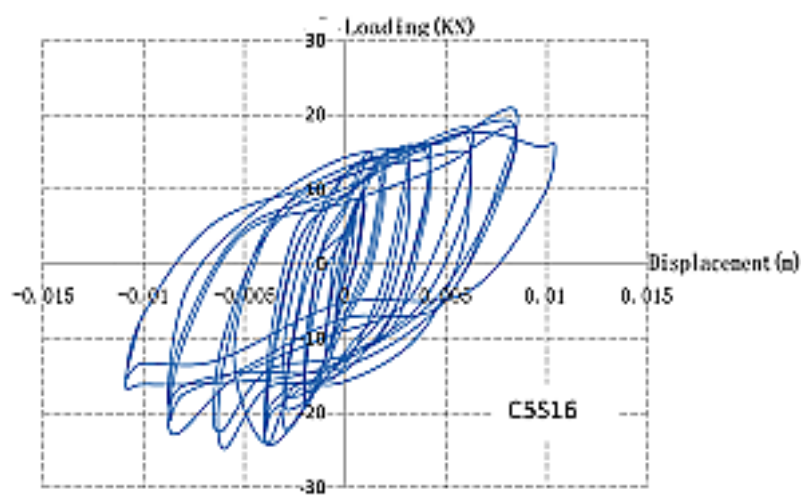

(a)

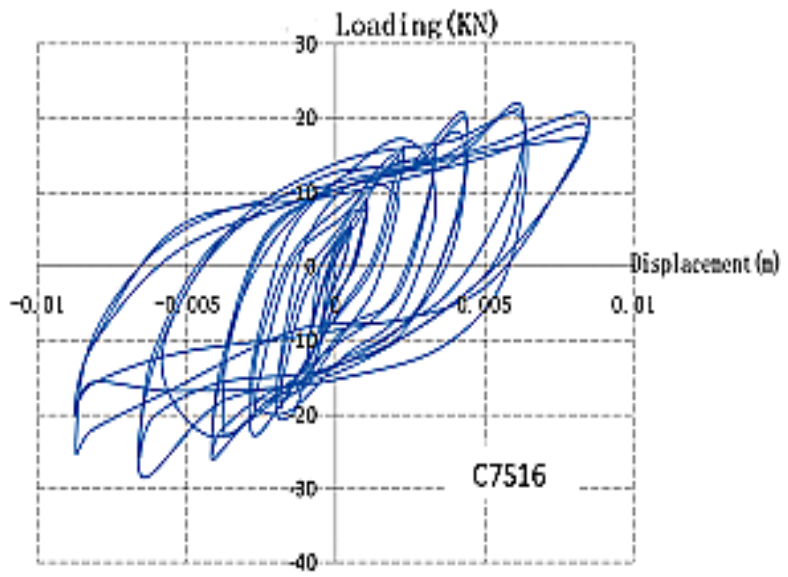

(b)

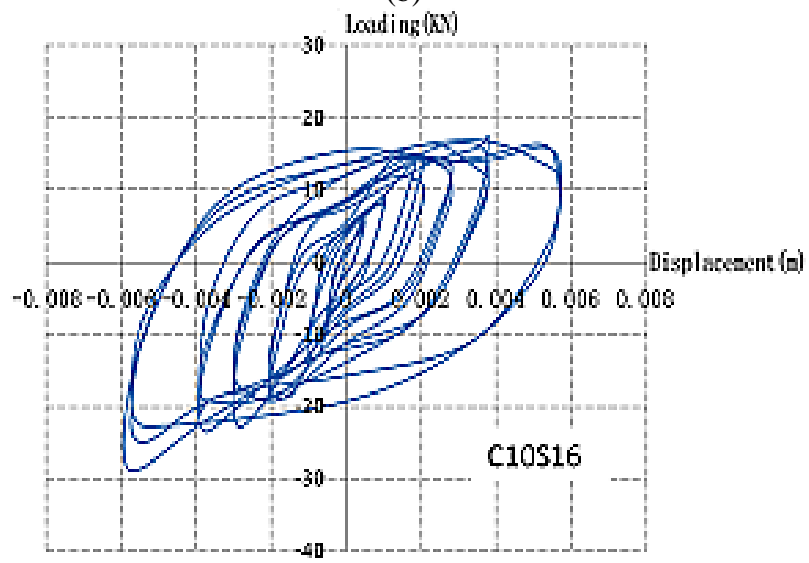

(c)

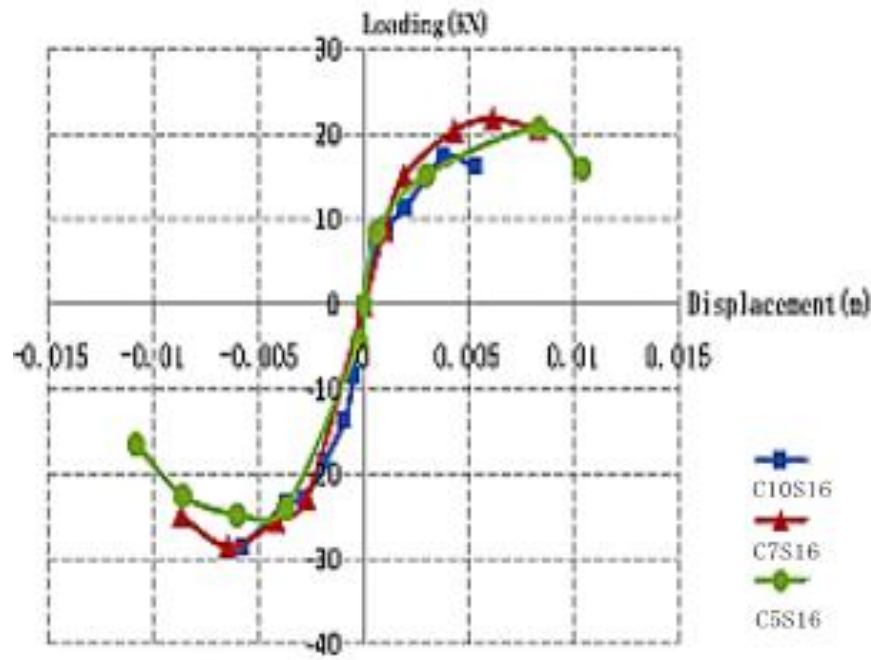

(d)

Fig. 7. Hysteretic behavior for different edge distances.

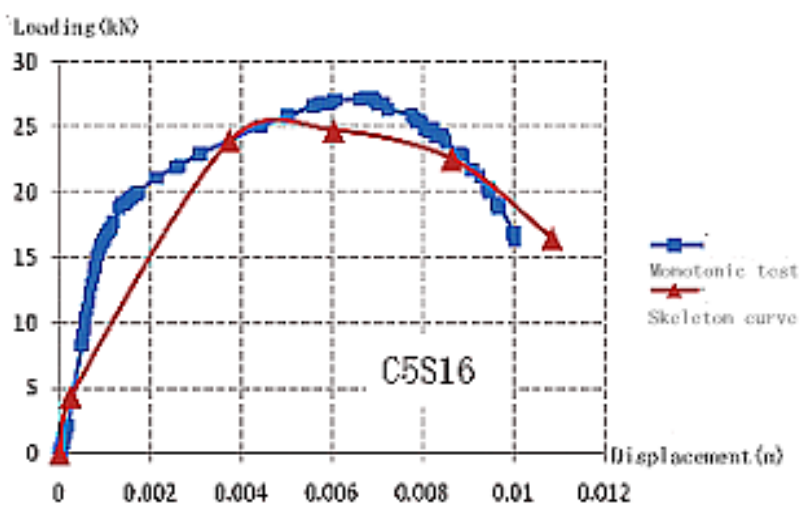

(a)

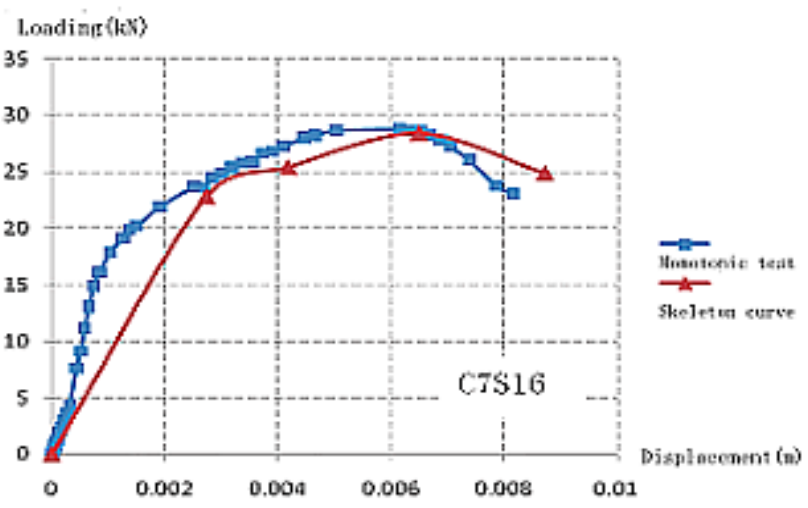

(b)

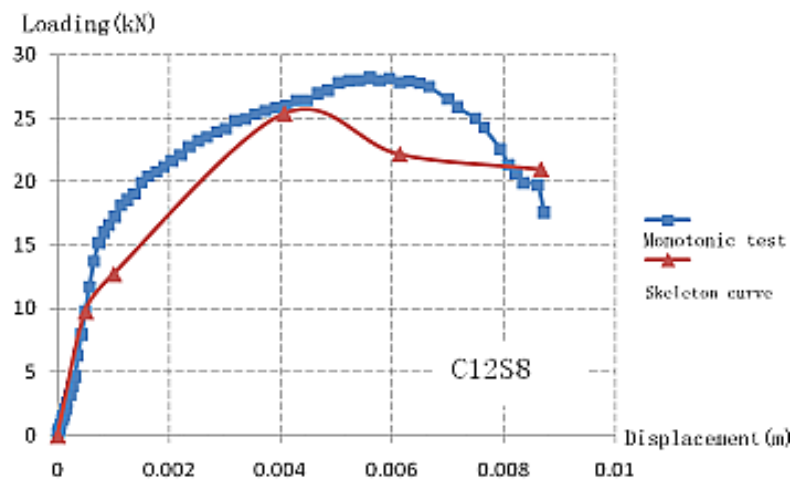

(c)

Fig. 8. Oad-displacement comparisons for three kinds of edge distance in static and dynamic 
Fig. 8 presents load-displacement comparisons for three kinds of edge distance in static and dynamic loading respectively, which indicates that under the cyclic loading anchorage strength has a certain loss and rigidity has significant reduction, especially after anchor steel yielding.

\section{CONCLUSIONS}

To investigate the behavior of steel-to-concrete connection under cyclic loading, 3D FE model is employed to give numerical analysis and the results can be shown as following:

1) There is strength reduction for steel-to-concrete connection under cyclic loading compared with static loading capacity, so reasonable embedment depth, spacing and edge distance should be considered in seismic design.

2) In parameter analysis of spacing, the strength and rigidity for connection with spacing $5 \mathrm{~d}$ has worse value, while anchors with spacing $12 \mathrm{~d}$ behave better performance in capacity and seismic energy dissipation.

3) As for the study of edge distance, compared with static results the ultimate capacity of anchor in small edge distance has significant reduction because of incomplete concrete cone, connection with edge distance $10 \mathrm{~d}$ under cyclic loading presents similar anchorage behavior with strength in static test. The minimum edge distance of $8 \mathrm{~d}$ is proposed.

\section{ACKNOWLEDGEMENTS}

This research was financially supported by Project of Shandong Province Natural Science Foundation Program(Granted No.ZR2014EL037) and Project of Shandong Province Higher Educational Science and Technology Program(Granted No.J13LG06).

\section{REFERENCES}

[1] L. Su and Z. D. Lu, Journal of Harbin Institute of Technology, 2010.

[2] L. Z. Wu, Earthquake Resistant Engineering and Retrofitting, 2013.

[3] S. Y. Kim, C. S. Yu, and Y. S. Yoon, Nuclear Engineering and Design, vol. 228, pp. 273-281, 2004.

[4] Ghobarah and T. S. Aziz, Nuclear Engineering and Design, vol. 228, pp. 228-377, 2004.

[5] D. Lotze, R. E. Klinger, and H. L. Graves, ACI Structural Journal, vol. 98 , pp. 525-536, 2001
[6] Y. G. Zhang, R. E. Klingner, and H. L Graves, ACI Structural Journal, vol. 98, pp. 811-822, 2001.

[7] S. Yilmaz, M. A. Özen, and Y. Yardim, Construction and Building Materials, pp. 861-866, 2013.

[8] Ö. Çalışkan, S. Yılmaz, H. Kaplan, and N. Kıraç, Construction and Building Materials, vol. 38, pp. 723-730, 2013.

[9] R. A. Cook and R. E. Klingner, Journal of Structural Engineering, vol. 118, pp. 645-1665, 1992.

[10] M/ Garrido, J. R. Correia, T. Keller, and F. A. Branco, Composite Structures, vol. 134, pp. 255-268, 2015.

[11] C. Mahrenholtz, R. Eligehausen, and H. W. Reinhardt, Engineering Structures, vol. 100, pp. 645-655, 2015.

[12] L. Contrafatto and R. Cosenza, Construction and Building Materials, vol. 68, pp. 355-369, 2014.

[13] F. X. Wan and W. Z. Zheng, Journal of Harbin Institute of Technology, vol. 44, pp. 11-16, 2012.

[14] N. Pinoteau, International Journal of Adhesion and Adhesive, vol. 31, pp. 851-861, 2011.

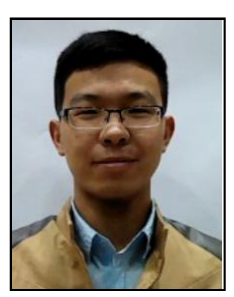

Lei Xu was born in Wei fang, Shandong province, P.R.China in 1990. He got his bachelor degree of civil engineer in University of Ji nan in 2015. His current research focuses on the fire behavior of postinstalled anchor. $\mathrm{He}$ is still graduate student in University of Ji nan now.

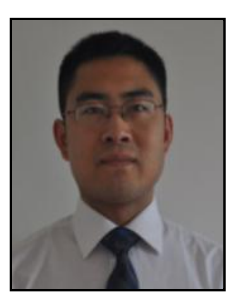

Qun Xie was born in Liao Cheng, Shandong province, P.R.China in 1979. He got his PhD degree of structural engineering in Tongji University in 2006. His current research focuses on the fire behavior of post-installed anchor.

He has been working in University of Jinan since 2006 and he has studied in Lehigh University, USA as a visiting scholar in 2012. Now he is the vice dean of School of Civil Engineering and Architecture. He has published 20 papers in journals and many articles have been tagged by EI and SCI. He has conducted several research projects such as National Natural Science Foundation of China as project principal and main researcher.

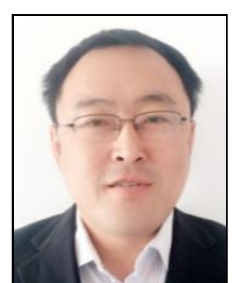

Chang-Liang Sun was born in $\mathrm{Zi} \mathrm{Bo,} \mathrm{Shandong}$ province, P.R.China in 1977. He got his bachelor degree of civil engineer in Shandong Jianzhu University in 2000. His current research focuses on the eco-friendly building materials and fireproof materials.

He has been working in Jinan Billion Machinery \& Equipment Co., Ltd since 2004. Now he is the director of Research and Development Department. $\mathrm{He}$ has published several papers in journals. As a registered structural engineer, he has conducted many design projects. 